\title{
Comparing the regenerative effects of silymarin and apricot on liver regeneration after partial hepatectomy in rats.
}

\author{
İsmet Yilmaz ${ }^{*}$, Hamit Sinan Hatipoğlu ${ }^{2}$, Elif Taşlidere ${ }^{3}$, Merve Karaaslan ${ }^{4}$ \\ ${ }^{1}$ Department of Pharmacology, Inonu University, Malatya, Turkey \\ ${ }^{2}$ Department of General Surgery, Adiyaman University, Adiyaman, Turkey \\ ${ }^{3}$ Department of Histology-Embryology, Bezmialem Vakif University, İstanbul, Turkey \\ ${ }^{4}$ Department of Chemistry, Inonu University, Malatya, Turkey
}

\begin{abstract}
This study is aimed to investigate and compare the regenerative effects of Silymarin (SLM); and Sun Dried Organic Apricot (SDOA) on liver regeneration after 70\% Partial Hepatectomy (PH) in rats. Rats mean weighing was $238.1 \pm 17.8 \mathrm{~g}$, and they were randomly divided into the five groups. During the $17 \mathrm{~d}$ of the study period, the following feed and drug administration order was maintained: group 1 (sham) $(n=6)$ and group $2(n=8)$ were fed with standard rat chow, group $3(n=8)$ was fed with standard rat chow and given additionally daily $100 \mathrm{mg} / \mathrm{kg}$ dose of silymarin extract by gavage, group $4(\mathrm{n}=8)$ was fed with $10 \%$ supplemented SDOA to chow and, in addition, they were given daily $100 \mathrm{mg} / \mathrm{kg} \mathrm{dose}$ silymarin extract by gavage, and group $5(n=8)$ was fed with $10 \%$ supplemented SDOA to chow. Water was given ad-libitum to all groups. After a week, group 1 had a laparoscopic procedure; the others underwent a $70 \%$ PH. On $18^{\text {th }} \mathrm{d}$ of the study, all rats were humanely sacrificed. Taken liver tissue samples of all groups were used to histopathological and tissue biochemical examination. Approximately $10 \mathrm{ml}$ blood samples were taken and the obtained serum samples were used for measurement of serum Aspartate Transaminase (AST) AST, Alanine Transaminase (ALT) and Alkaline Phosphatase (ALP) levels. The results of the present study revealed a remarkable protective effect of silymarin rather than SDOA based on the histopathological and Proliferating Cell Nuclear Antigen, (PCNA). PCNA findings and liver tissue/serum biochemical parameters. Therefore, before 7 and after $10 \mathrm{~d}$ of $\mathbf{P H}$, silymarin administration have shown beneficial effect than SDOA consumption on liver regeneration of rats.
\end{abstract}

Keywords: Silymarin, Apricot, Partial hepatectomy, Liver regeneration, Rat.

Accepted on January 30, 2018

\section{Introduction}

In mammals, after surgical resection or $\mathrm{PH}$, the regeneration process is dependent on the capacity of the remnant liver. There are some effective components as growth-related genes, nutritional status, and pharmacological agents. In rats, a regeneration process is completed within 7-10 d after $\mathrm{PH}[1,2]$. Hepatectomy or liver injury occasion oxidative stress and raise Reactive Oxygen Species (ROS) levels. For supporting the regeneration of the remnant liver, antioxidant consumption/ supplementation has been reported by some researchers, thus fruits have protective and/or preventive effects against the damage caused by free radicals, (as a natural antioxidant), and also carotenoids are playing a significant role in normal cellular activity $[3,4]$. In this context, apricot (Prunus armeniaca L.) is considered as a rich source of dietary carotenoids and among the Malatya apricot varieties, Kabaaş1 have one of the highest total carotenoid contents [4-6]. Liver diseases are extensive worldwide and characterized by a progressive/chronic hepatitis, fibrosis, cirrhosis, and Hepatic Cell Carcinoma (HCC). It is reported that, HCC is one of the most common cancers and fatal diseases and associated with high morbidity and mortality in the world. And because of $\mathrm{HCC}$, surgical resection is to be the most optimal treatment approach, but only $10-20 \%$ of HCC patients are candidates for surgery, and also the reiterations can be as high as $50 \%$ within several years of surgery [7]. In preventive control attempts, the phytochemicals are properly accepted as beneficial pharmacological ingredients and they endorsed treatment options for various conditions. In this context, it has been accepted that the natural dietary polyphenolics are obtained from variant fruits and vegetables. These are phytochemicals and bioactive food components, (as anthocyanidins, catechins, curcumin, genistein, lycopene, resveratrol, quercetin and $\beta$ caroten) [6-8]. Here, El-Adawi et al. reported that dietary polyphenols have beneficial effect on human health by means of free radical scavenging, metal chelation and modulation of 
enzymatic activity and alteration of signal transduction pathways [9].

Different plant parts have been used as traditional medicines for 2000 years. Silybum marianum has long been used to treat stomach, liver and gall bladder disorders. The most important use of this medicinal plant is its liver protecting property (cirrhosis, jaundice, hepatitis and liver poisoning). In addition to these, the major medicinal activities of Silybum are anticancer, antidepressant, antioxidant, cardio protective, demulcent, digestive tonic, hepatoregenerative, immunostimulatory and as a neuroprotective [9-11].

Silybum marianum (L.) Gaerth is a member of Asteraceae, including two or three species distributed in Mediterranean region and introduced elsewhere [12]. Silymarin (Silybum marianum) is a standardized extract of the milk thistle or St. Mary thistle or deve dikeni (in Turkish) [13]. Since almost 2000 years, as a natural medicament its seeds have been used for liver diseases and it contains pharmacologically effective substances which are silybin (50-60\%), isosilybin (5\%), silychristin (20\%) and silydianin (10\%) [14,15]. Silymarin acts in four different ways: as an antioxidant, absorber, stabilizer and regulator [15]. The results of many experimental studies conducted on hepatoprotective effects of silymarin were briefly reported by Suchy et al. and $\mathrm{Wu}$ and Tsai $[15,16]$. Our previous study focused on regenerative effects of $5 \%$ SDOA consumption after $\mathrm{PH}$ in rats [4]. However, there were not found any scientific reports about comparing the regenerative effects of $100 \mathrm{mg} / \mathrm{kg} /$ day dose silymarin extract oral administration and $10 \%$ SDOA consumption in case of $70 \%$ $\mathrm{PH}$ before 7 and after $10 \mathrm{~d}$ in rats. Therefore, the present study has been undertaken to investigate and compare regenerative activity of Silymarin and SDOA.

\section{Materials and Methods}

\section{Animals and study protocol}

This study was carried out on 38 female and 10-12 months of age Sprague Dawley rats. The study protocol was confirmed by the Ethic Committee Faculty of Medicine, Inonu University (2013/A-04) Malatya, Turkey. The rats were provided from the Experimental Animal Research and Production Center of Inonu University. At the beginning of the study, the average body weight of the rats was $238.1 \pm 17.8 \mathrm{~g}$ (Mean \pm SD). The rats were randomly divided into five groups and the following feed and drug administration order was maintained during $17 \mathrm{~d}$ study. Group 1 (sham) $(n=6)$ and group $2(\mathrm{PH})(\mathrm{n}=8)$ were fed with standard rat chow, group $3(\mathrm{SLM}+\mathrm{PH})(\mathrm{n}=8)$ was fed standard rat chow and additionally they were given 100 $\mathrm{mg} / \mathrm{kg} /$ day dose of silymarine extract (MP Biomedicals, LLC, France CAT no:198792) by intragastric gavage, group 4 (SLM $+\mathrm{SDOA}+\mathrm{PH})(\mathrm{n}=8)$ was fed with $10 \%$ supplemented SDOA to chow and additionally they were given at $100 \mathrm{mg} / \mathrm{kg} / \mathrm{d}$ dose silymarin extract by intragastric gavage, and group 5 (SDOA $+\mathrm{PH})(\mathrm{n}=8)$ was fed with $10 \%$ supplemented SDOA to chow and water was given ad-libitum to all groups. After a week (on $7^{\text {th }} \mathrm{d}$ of study), group 1 had a laparoscopic procedure; the other groups underwent a $70 \% \mathrm{PH}$. On the $18^{\text {th }} \mathrm{d}$ of the study, all rats were anesthetized by intraperitoneal injection of ketamine +xylazine and approximately $10 \mathrm{ml}$ blood samples were taken by intracardiac puncture and they were humanely sacrificed. Taken liver tissues were excised and weighed, and then this tissue samples were used for histopathological and tissue biochemical examinations. Taken blood samples were centrifuged at 3000 r.p.m. for 10 minutes and the obtained serum samples (within an hour) were stored at $-20^{\circ} \mathrm{C}$ until analysis and these samples were employed for measurement of serum AST, ALT and ALP levels.

\section{Surgical procedure}

In the present study, all surgical procedures of laparotomy and $70 \% \mathrm{PH}$ were performed under sterile conditions. After intraperitoneal injection of ketamine $(50 \mathrm{mg} / \mathrm{kg})$ and xylazine $(10 \mathrm{mg} / \mathrm{kg})$ as anesthetic agents, $\mathrm{PH}$ was performed according to Higgins and Anderson's method [17]. In supine position, an upper midline incision of the abdomen was followed by retraction of the xyphoid cartilage for adequate exposure of the liver and division of hepatic ligaments. The right median, left lateral and median liver lobes (anterior lobes), which correspond to approximately $70 \%$ of the total liver mass, were resected while the right lateral and caudate lobes (posterior lobes) were left intact. After irrigation of the abdomen with warm saline, the peritoneum and the skin were closed with running 4-0 and 3-0 sutures, respectively. Postoperatively, the animals were allowed to recover from anesthesia and had free access to food and water until the final experiment. For sham surgeries, livers were externalized and gently palpated to mimic the surgical stress of the $\mathrm{PH}$ procedure. Animals undergoing laparotomy and $\mathrm{PH}$ not received any antibacterial and/or other conservatives.

\section{Statistical analyses}

For the evaluation of serum parameters; the data were expressed as median with min and max values. The Kruskal Wallis $\mathrm{H}$ test was used for statistical analysis of serum biochemical variables, and pairwise comparisons were made by means of Mann Whitney U test with Bonferroni correction. A p value lower than 0.05 was considered as statistically significant. IBM SPSS Statistics 23.0 for Windows was employed for all analyses. The values are given as median (min-max).

For the evaluation of histopathological score and Superoxide Dismutase (SOD), Malondialdehyde (MDA), Catalase (CAT) and Glutathione (GSH) parameters; the data were analysed using the SPSS software program for Windows, version 18.0 (SPSS, Inc., Chicago, IL). The normality of the distribution was confirmed using the Kolmogorov-Smirnov test. According to the results obtained from the normality test, one-way Analysis of Variance (ANOVA) test was used for the statistical analysis, as appropriate. Multiple comparisons were carried out by Tamhane's test (for non-homogeneous variances) after the ANOVA test. 


\section{Histological assessment}

Liver tissue was fixed in 10\% formalin and was embedded in paraffin. Tissue sections were cut at $5 \mu \mathrm{m}$, mounted on slides, stained with Hematoxylin-Eosin (H-E) for general liver structure. The liver damage severity was semi quantitatively assessed as follows; inflammatory cell infiltration, congestion. Microscopic damage was identified as absent (0), slight (1), moderate (2), and severe (3), for each criterion. The sections were examined by a Leica DFC 280 light microscope by histology unaware of the status of animals.

For immunohistochemical analysis, thick sections of liver were taken onto polylysine coated slides. After rehydrating, the samples were transferred to citrate buffer $(\mathrm{pH}$ 7.6) and heated in a microwave oven for $20 \mathrm{~min}$. After cooling for $20 \mathrm{~min}$ at room temperature, the sections were washed with Phosphate Buffered Saline (PBS). Then, the sections were kept in $0.3 \%$ $\mathrm{H}_{2} \mathrm{O}_{2}$ for $7 \mathrm{~min}$ and afterward washed with PBS. The sections were incubated with Proliferating Cell Nuclear Antigen (PCNA) (Biocare) antibody for $30 \mathrm{~min}$ rinsed in PBS and incubated with biotinylated goat anti-polyvalent for $10 \mathrm{~min}$ and streptavidin peroxidase for $10 \mathrm{~min}$ at room temperature. This staining procedure was completed with chromogen+substrate for $15 \mathrm{~min}$ and slides were counter stained with Mayer's hematoxylin for $1 \mathrm{~min}$, rinsed in tap water and dehydrated. A PCNA kit was used in accordance with the manufacturer's instructions except minor revision. PCNA positive cells stained as brown color. PCNA $(+)$ cells were counted in the 10 microscopic areas under 40X objective magnification using Leica Q Win Image Analysis System (Leica Micros Imaging Solution Ltd. Cambridge, UK). The sections were examined using a Leica DFC280 light microscope.

\section{Biochemical evaluation}

Preparation of tissue homogenates: Tissues were homogenized (PCV Kinematica Status Homogenizator, Switzerland) in ice-cold PBS ( $\mathrm{pH}$ 7.4). The homogenate was sonicated with an ultrasonic AQ1 tor (Branson sonicator 450) by three cycles ( $20 \mathrm{~s}$ sonications and $40 \mathrm{~s}$ pause on ice) and centrifuged $\left(15,000 \mathrm{~g}, 10 \mathrm{~min}, 4^{\circ} \mathrm{C}\right)$, and cell-free supernatant was subjected to enzyme assay immediately. The determination of protein levels of the tissue samples was measured by the Bradford method [18]. Absorbance measurement was taken at $595 \mathrm{~nm}$ using an ultraviolet-visible spectrophotometer. Bovine serum albumin was used as protein standard.

\section{Determination of MDA levels}

The analysis of lipid peroxidation was carried out as described by Buege and Aust with a minor modification [19]. The reaction mixture was prepared by adding $250 \mathrm{ml}$ homogenate into $2 \mathrm{ml}$ reaction solution (15\% trichloroacetic acid: $0.375 \%$ thiobarbituric acid: $0.25 \mathrm{~N}$ hydrochloric acid, $1: 1: 1, \mathrm{w} / \mathrm{v})$ and heated at $1000^{\circ} \mathrm{C}$ for $15 \mathrm{~min}$. The mixture was cooled to room temperature, centrifuged $(10,000 \mathrm{~g}$ for $10 \mathrm{~min})$, and absorbance of the supernatant were recorded at $532 \mathrm{~nm}$. 1,1,3,3Tetramethoxypropane was used as Malondialdehyde (MDA) standard. MDA results were expressed as nanomoles per milligram protein in the homogenate.

\section{Determination of GSH levels}

The formation of 5-thio-2-nitrobenzoate was followed spectrophotometrically at $412 \mathrm{~nm}$. The amount of GSH in the extract was determined as nanomoles per milligram protein utilizing a commercial GSH as the standard [20].

\section{Determination of SOD activities}

SOD activity in the supernatant fraction was measured using the xanthine oxidase/cytochrome c method [21] where one unit of activity is the amount of enzyme needed to cause halfmaximal inhibition of cytochrome $\mathrm{c}$ reduction. The amount of SOD in the extract was determined as ng of enzyme per as mg protein, utilizing a commercial SOD as the standard.

\section{Determination of CAT activities}

CAT activity was measured at $37^{\circ} \mathrm{C}$ by following the rate of disappearance of hydrogen peroxide $\left(\mathrm{H}_{2} \mathrm{O}_{2}\right)$ at $240 \mathrm{~nm}$ $\left(\varepsilon_{240}=40 \mathrm{M}^{-1} \mathrm{~cm}^{-1)}\right.$ [22]. One unit of catalase activity is defined as the amount of enzyme catalysing the degradation of $1 \mu \mathrm{mol}$ of $\mathrm{H}_{2} \mathrm{O}_{2}$ per min at $37^{\circ} \mathrm{C}$ and specific activity corresponding to the transformation of substrate (in $\mu \mathrm{mol})\left(\mathrm{H}_{2} \mathrm{O}_{2}\right)$ per min per mg protein.

\section{Results}

\section{The liver weights}

On the $7^{\text {th }} \mathrm{d}$ of study, in all $\mathrm{PH}$ groups, the average resected liver weights of rats were determined as 5.48-6.26 $\mathrm{g}$ and, on $11^{\text {th }} \mathrm{d}$ of after $\mathrm{PH}$, the average regenerated liver weights which remnant liver of rats was determined as 7.64-8.77 g. There were not any statistically significant differences determined among the regenerated liver weights of all $\mathrm{PH}$ groups. It is necessary to emphasize that, in case of $\mathrm{PH}$ operations, macroscopic appearance (as color, stiffness and consistency) of the livers of group 3 was very different from the others.

\section{The serum liver enzymes}

Among the serum and liver enzyme levels of all groups, only ALP parameters showed statistically significant differences (Table $1, \mathrm{p}<0.0001$ ). In groups 2 and 3, a significant increase was shown on serum ALP levels, but this significant increase was not detected in group 4 and 5 (Table 1).

\section{Light microscopic evaluation}

The sham group showed a normal appearance of the liver cells (Figure 1A). However, in the $\mathrm{PH}$ group, histopathological alterations were observed such as inflammatory cell infiltration around the portal triad and central vein (Figure 1B). In addition, congestion was determined in a sinusoidal area (Figure 1C). The histopathological score of the PH group was found to be significantly increased when compared to the sham 
group $(\mathrm{p}<0.05)$. In, a group 3-5, although the liver tissue preserved its normal histological appearance, mild inflammatory cell infiltration still was marked in some areas
(Figures 1D-1F). The histopathological score of 3 and 4 groups was significantly lower than that of group $5(p<0.05)$. The microscopic damage score is shown in Table 2.
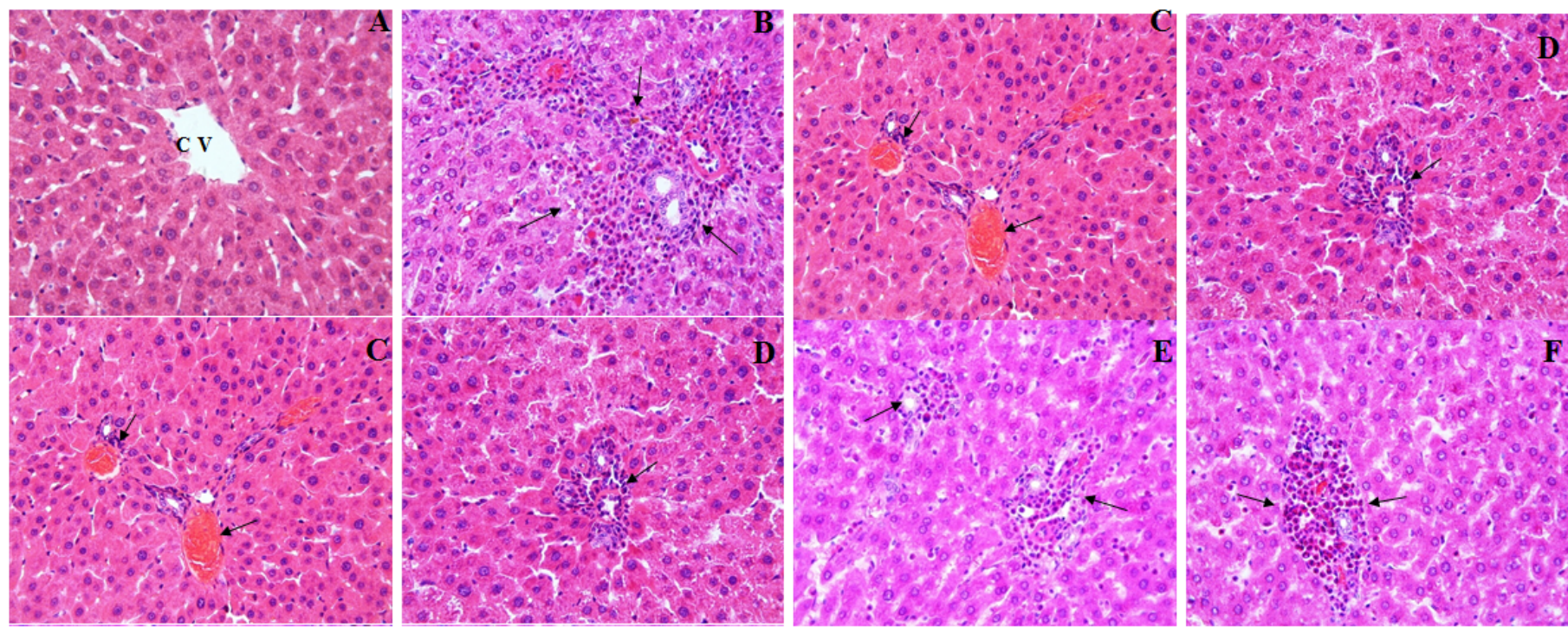

Figure 1. A: Sham group: the normal hepatocytes architecture and the Central Vein (CV); B: Group 2: notice cellular infiltration around portal triad and central vein (arrows); C: Group 2: the appearance of congestion (arrows) group 3; D: and group 4; E: Hepatocytes is almost intact but mild cellular infiltration is still present in around portal area (arrows); F: Group 5: the appearance of mild cellular infiltration H and E; X40.

\section{Immunohistochemistry (PCNA immunoreactivity)}

Hepatocyte nuclei showing a positive reaction by the PCNA immunostaining method were stained brown (Figure 2A). A statistically significant increase in the number of PCNA $(+)$ cells was detected in the PH groups compared with the sham group $(p<0.05)$ (Figure $2 \mathrm{~B})$. Additionally, in groups $3-5$, the number of PCNA $(+)$ cells was higher than those of group 2 $(\mathrm{p}<0.05)$ (Figures 2C-2E). However, a statistically significant increase in the number of PCNA $(+)$ cells in group 3 was detected in comparison with the other groups $(\mathrm{p}<0.05)$. Mean numbers of PCNA $(+)$ cells are summarized in Table 3.

In the present study, determined and observed histopathological alterations and their statistical significances among groups are shown in Table 2. In terms of mild inflammatory cell infiltration, the lowest values were observed in group 3 than the other groups, and it may be said that SDOA supplementation antagonized this positive immunostimulatory and antioxidant effect of silymarin $(\mathrm{p}<0.05)$ (Table 2). Here, similar histopathological scores of group 4 and 5 supported the above suggestions. On the other hand, based on the number of cells stained with PCNA, SDOA supplementation showed a synergistic effect of silymarin $(p<0.05)$ (Table 3$)$. This is because only silymarin application (group 3) or SDOA consumption (group 5) was not affected as group 4 (Table 3). The histopathological score of the $\mathrm{PH}$ group was found to be significantly increased when compared to the sham group $(p<0.05)$. The histopathological score of group 3 and group 4 was significantly lower than that of group $5(\mathrm{p}<0.05)$. The number of PCNA $(+)$ and its mean values were given under Table 3 , the number of PCNA $(+)$ of silymarin treatment groups 3 and 4 displayed a statistically significant difference compared to the other groups $(\mathrm{p}<0.05)$ (Table 3$)$.

In the present study, mean liver tissue SOD and CAT activities of all the groups were similar, the SOD levels of the groups were very close to each other and CAT levels were a bit different among groups and no significant difference was detected (Table 4). But there were statistically significant differences determined among MDA and GSH levels of groups, and among groups their significances are shown in Table 4. The lowest GSH and highest MDA levels were determined in the group 2.

Significant increases in GSH and decreases in MDA levels were observed in the group 2 compared to receiving SLM, and SDOA groups (Table 4). Based on MDA levels decrease of 3 and 4 groups, SDOA consumption showed a synergistic effect with silymarin (Table 4). However, a significant decrease was identified in MDA levels only in group 3 and 4, on the other hand, SDOA consumption was not the only decreasing effect on MDA levels (Table 4). The same situation was absolutely realistic increase effects of GSH levels and, in addition, it is emphasized that the decreases on MDA and an increase in GSH levels have a scientifically importance for the evaluation of tissue regeneration and oxidative stress (Table 4). However, similar situation was not shown on SOD and CAT parameters (Table 4). The SOD value are shown as ng/mg protein, the CAT, MDA and GSH values are shown as $\mu \mathrm{mol} / \mathrm{mg}$ protein in Table 4. Considering these results; that may be surely say, there are not any synergicistic and/or antagonistic effects between silymarin and SDOA consumption in rats. 


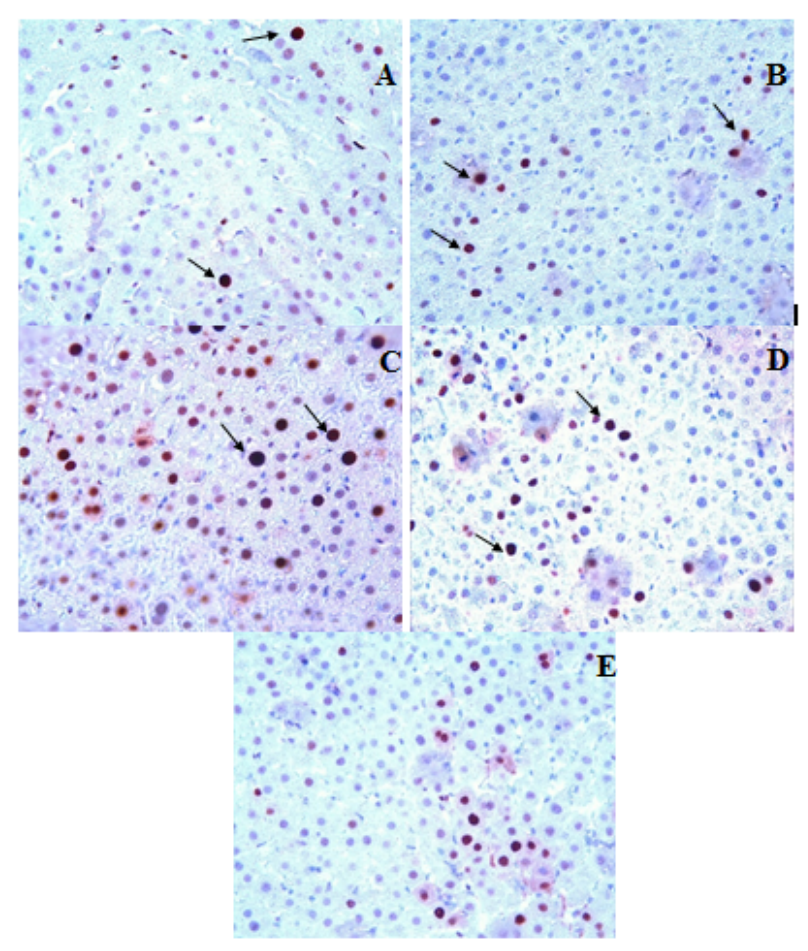

Figure 2. A: Sham; B: PH; C: SLM+PH; D: SLM+SDOA+PH; E: SDOA+PH groups: the appearance of PCNA (+) cells (arrows). $P C N A ; X 40$.

\section{Discussion}

The present study investigated and compared regenerative activity of Silymarin and SDOA in rats. We found that; the mean levels of ALP $(p<0.0001)$, and tissue MDA, GSH $(\mathrm{p}<0.05)$ levels were significantly affected by silymarin and/or SDOA consumption before 7 and after $10 \mathrm{~d}$ of $\mathrm{PH}$ in rats. And also histopathological findings of the present study have been supporting these results.

It is reported that, chronic liver diseases are common worldwide and these are characterized by a progressive evolution from steatosis to hepatitis, fibrosis, cirrhosis, and hepatocellular carcinoma and are associated with high morbidity and mortality. In mammalian body, the liver is the only organ that quickly regenerates after injury or surgical resection $[2,7]$. In the present study, silymarin dose was the same as Chen et al. [23], two times higher than Horvath et al. [24] and higher than Raskovic et al. studies [25]. Yang et al. [7] dose of silymarin were two times higher and El-Adawi et al. [9] dose was 7.5 times lower than ours, but Megahed et al. [26] dose was one out of five from us. And the administration routes were same with Raskovic et al. [25], Yang et al. [7], ElAdawi et al. [9], Megahed et al. [26] and Chen et al. [23] studies and different from Horvath et al. study [7,9,23-26]. And also SDOA rate (10\%) was same with Vardi et al [6], Yilmaz et al. [27] and Parlakpinar et al. [28] studies, and two times more than Yilmaz et al. [4,6,27-29]. Of course, all of these studies are not $\mathrm{PH}$ in rats, some of them are $\mathrm{PH}$ and the others are drugs induced hepatotoxicity or other studies.
It has been reported by some researchers that several factors improving and promoting the liver regeneration and some of them are as follows; prostaglandin E2 enhances the proliferation of hepatocytes by increasing intracellular cyclic AMP [30], nitric oxide, a flow-dependent factor is a trigger to initiate the regeneration process [31], antioxidant treatment with vitamin E [32], carvacrol [33], prostaglandin E1 [34], resveratrol and melatonin [35], Triiodothyronine (T3) [36], beneficial effects of clinoptilolite [37] and SDOA [4].

Oxidative stress results from an oxidant/antioxidant imbalance in favor of oxidants. GSH reacts directly with ROS and electrophilic metabolites, so decreased GSH contents indicate increased oxidative stress. Additionally, the cytosols were used for the estimation of the activities of SOD and it is considered as the $1^{\text {st }}$ line of defense against superoxide anions produced heavily during all redox cyclings [38]. It is reported by Yao et al. that MDA formation is usually used as a biomarker of freeradical-mediated lipid peroxidation which was increased in regenerating liver after $\mathrm{PH}$. And also $\mathrm{PH}$ impairs the antioxidative system, such as SOD and GSH, which can offer protection from cell damage by scavenging superoxide anion radical in the upper stream of the reactive oxygen metabolism cascade. Impaired antioxidant defenses decrease oxidative phosphorylation capabilities to finally impede liver regeneration after $\mathrm{PH}$; however, GSH was increased during the latter phase after $\mathrm{PH}$ [2]. Our results shown in Table 4 have supported a decrease in MDA and an increase in GSH, thus the oxidant/antioxidant balance of remnant liver is positively supported by silymarin application or SDOA consumption.

That is in accordance with the commonly accepted view, the serum levels of the marker enzymes (as ALT) return to normal with the healing of hepatic paranchyma and regeneration of hepatocytes. The efficacy of any hepatoprotective drug or plant extract as silymarin dependent on its capacity reduces the harmful effect and restores the normal hepatic physiology, so it has been indicated that the protection of structural integrity of hepatocytic cell membrane or regeneration of damaged liver cells have been reported by Osadebe et al. [39]. Our serum AST and ALT levels were close to Ozturk et al. [13] study (except their $\mathrm{CCl}_{4}$ group), but our ALP values were very higher than their results. Of course, their study design, the used animals and autoanalyser are different from ours (Table 1). The ALT levels of the present study were lower than Malik et al.'s study [36]. On the other hand, there were not any statistically significant differences determined among serum AST and ALT levels of groups. Likewise, the AST and ALT results of the present study are in accord with our previous studies as ALP in female rats $[4,27,29]$. Serum ALT, ALP and AST values are shown as median with min and max and as (U/L) (Table 1). In the present study, MDA content in liver tissue homogenate was elevated in PH rats, and group 4 showed a decrease effect on MDA levels, but only SDOA was not effective as the combination (Table 4). In the case of PH (before 7 and after 10 $\mathrm{d}$ of $\mathrm{PH}$ ), silymarin and SDOA treatment significantly inhibited the elevation of MDA. The present study's MDA levels were very low, SOD and CAT levels were significantly different from Yilmaz et al. [4], but interestingly, SOD and 
CAT levels (present and Yilmaz. et al) [4] of both studies were not shown statistically significances (Table 4).

The same situation is true for serum AST and ALT levels of both studies (present and Yilmaz et al. [4]. The AST levels of the present study were very close and ALT levels were a bit lower than Yilmaz et al. [4]. It may be surely said that before and/or after PH operations (either 18 or $21 \mathrm{~d}$ period) $\% 5$ or 10 SDOA consumption were not effective on serum AST and ALT levels and tissue SOD and CAT levels in female rats. When liver tissue MDA levels of present and our previous study are compared, 4 especially postoperative time and/or SDOA rates were effective (Table 4). In our another previous study [27], only SDOA consumption showed significant differences on serum ALP, AST and ALT levels by rates and periods in female rats, but there were no any operation or surgical procedure in that study (Table 4). It is indicated that silymarin application and/or SDOA consumption has positive effects on tissue MDA and GSH activities and this positive effects may be due to their rich antioxidant contents. Yao et al. [2] reported that the tissue MDA levels are usually used as a biomarker of free-radical mediated lipid peroxidation as well as $\mathrm{GSH}$, which can offer protection from cell damage by scavenging superoxide anion radical in the upper stream of the reactive oxygen metabolism cascade. Vardi et al. [6] reported that apricot was found to be more effective than $\beta$-carotene increase in SOD, CAT and GSH levels and decrease in MDA levels of the intestinal tissue. Although both studies (present and theirs) are extremely different from another, these findings in MDA, SOD, CAT and GSH levels of liver and intestine have a scientific importance because of the oxidant/antioxidant balance in favor of oxidants.

Our liver tissue GSH levels (except control) were very close to Raskovic et al. study [25], but CAT levels were very different, (if their CAT values were not summarized as nmol/mg of protein), their CAT levels of the first 2 groups were very close to ours, and their liver tissue MDA levels were very different from ours (Table 4). Our serum AST levels were very low, and ALT levels were a bit close to theirs (Table 1). These differences may originate from sub-species, breed, gender and numbers of used animal, and also used analytical method/ values and chemicals [25].

To evaluate the histopathological findings; it was seen that in group 2, notice cellular infiltration around portal triad and central vein (C) and the appearance of congestion, in group 3 (D) and group 4 (E) hepatocytes is almost intact but mild cellular infiltration is still present around the portal area (F), and in group 5, the appearance of mild cellular infiltration too (Figure 1). These positive effects may be related with the silymarin, which exhibits antioxidant, anti-inflammatory, hepatoprotection and growth modulatory effects and SDOA has a rich $\beta$-carotene (Tables 2 and 3 ). The antioxidant activity of phenolics (as flavonoids, phenolic acids, stilbenes) is principally due to their redox properties, which allow them to act as reducing agents, hydrogen donors and singlet oxygen quenchers [7]. Vardi et al. [6] reported that apricot was found more effective than $\beta$-carotene in preventing the inhibition of myeloperoxidase release from neutrophil cells. In addition, $\beta$ carotene which can be converted to retinoids (provitamin A), has effects on purine and pyrimidine synthesis, thus apricot facilitates such process by means of increasing the DNA synthesis and cell production in the gastrointestinal mucosa. Therefore, the important positive effects can be summarized as $\beta$-carotene $\rightarrow$ retinoids $\rightarrow$ increasing the purine and pyrimidine synthesis $\rightarrow$ increasing DNA synthesis and $\rightarrow$ cell production $\rightarrow$ and finally regeneration (Table 3 and Figure 2). Similarly, Yao et al. [2] reported that the rate of DNA synthesis correlates with cell proliferation, and also DNA synthesis indirectly indicates the ability of the liver to regenerate. The synthesis rate of hepatic DNA and protein after PH was accelerated by bicycle, which can enhance liver regenerative capacity after hepatectomy [2]. In addition, they emphasized that the regenerating liver requires enormous energy for its metabolic overload and hepatocellular glycogen level is a potentially important factor in maintaining hepatocellular integrity and function by generating ATP. When glycogen is consumed, rapid ATP depletion occurs; this eventually causes irreversible cell injury and necrosis. Again, they reported that glycogen content was remarkably reduced after $\mathrm{PH}$, but pretreatment with bicycle inhibited the reduction of glycogen, so providing an energy support for liver regeneration [2]. Our results of histopathological scores shown in Table 3 supported the above suggestions. Additionally, Yao et al. [2] reported that the regeneration process completes within 7-10 d after $\mathrm{PH}$ in rats, and also this information supported all the results above [2]. Malik et al. [36] were reported that, there was no significant difference in liver mass or total DNA or liver protein levels between the $\mathrm{T} 3$ in $\mathrm{PH}$ group and $\mathrm{PH}$-alone group when animals were killed $24 \mathrm{~h}$ after surgery. However, there was a significant difference among the groups $4 \mathrm{~d}$ after surgery, where the liver mass was increased in the group receiving T3 at $\mathrm{PH}$ compared to the $\mathrm{PH}$-alone group [25]. On the other hand, Zabielski et al. [1], suggested that the activity of pro-mitogenic intermediates of the sphingomyelin pathway of signal transduction was strongly modulated during the first $24 \mathrm{~h}$ of liver regeneration after $\mathrm{PH}$ in rats. Therefore, for the future experimental $\mathrm{PH}$ studies, the maximum $10 \mathrm{~d}$ period must be considered as a cornerstone. When serum and tissue biochemical parameters (Tables 1 and 4) and histo-pathological findings/evaluations (Figures 1 and 2 and Tables 2 and 3) are considered, this study might be a unique example of future studies.

In our previous study [4] Ki-67 findings were parallel to the present study's mean number of cells stained with PCNA in the liver and results of the histopathological score in all groups (Tables 2 and 3). It should be emphasized that before and after $\mathrm{PH}$, increased mitotic cell activity (especially in groups 3-5) were supported by silymarin application and/or SDOA consumption $(\mathrm{p}<0.05)$, (Tables 2 and 3 ). It was reported by Kirimlioglu et al. [35] and Seehofer et al. [40] that PH increases mitotic cell activity of the liver and Akcan et al. [41] noted that mitotic cells can be detected frequently at 24 and 48 $\mathrm{h}$ after $\mathrm{PH}$, increasing especially at 24 and $36 \mathrm{~h}$ and decreasing to lower levels at $96 \mathrm{~h}$ of $\mathrm{PH}$. In addition, silymarin 
administration similar histopathological findings as ameliorative effects were reported by El-Adawi et al. [9]. (Figures 1 and 2) (Tables 2 and 3). Hovarth et al. [24] reported that preoperative silibinin and/or vitamin E treatment because of their antioxidant capacity modulates the cellular immunoresponse and restores impaired liver function following $\mathrm{PH}$. In addition to the above findings, in the present study on $10^{\text {th }} \mathrm{d}$ of after $\mathrm{PH}$ determined average regenerated liver weights of rats were very close to the results of our previous study [4] and it confirms the information reported by Zabielski et al. [1] and Yao et al. [2] as the regeneration process completes within 7-10 d after PH. The contents of SDOA and standard rat chow, preparation of SDOA supplemented diet were given in Yilmaz et al. [42].

Table 1. Serum liver enzyme levels (All the variables were given with median with min-max).

\begin{tabular}{|c|c|c|c|}
\hline Groups $\downarrow$ and parameters $\rightarrow$ & AST (U/L) & ALT (U/L) & ALP (U/L) \\
\hline Group 1 (sham) $(n=6)$ & $121.5(79.0-178.0)$ & $56.5(43.0-112.0)$ & $190.0(126.0-221.0)$ \\
\hline Group $2(\mathrm{PH})(\mathrm{n}=8)$ & $105.5(86.0-176.0)$ & $65.5(41.0-86.0)$ & $318.5(278.0-546.0)^{\mathrm{a}}$ \\
\hline Group $3(\mathrm{SLM}+\mathrm{PH})(\mathrm{n}=8)$ & $129.5(86.0-154.0)$ & $72.0(50.0-83.0)$ & $366.0(296.0-683.0)^{\mathrm{a}}$ \\
\hline Group $4(\mathrm{SLM}+\mathrm{SDOA}+\mathrm{PH})(\mathrm{n}=8)$ & $114.0(95.0-142.0)$ & $49.0(33.0-71.0)$ & $290.0(200.0-400.0)^{b}$ \\
\hline Group $5(\mathrm{SDOA}+\mathrm{PH})(\mathrm{n}=8)$ & $129.0(80.0-228.0)$ & $63.0(24.0-120.0)$ & $296.0(206.0-409.0)^{b}$ \\
\hline$P$ value & 0.58 & 0.25 & $<0.0001$ \\
\hline
\end{tabular}

a: significantly different from Sham group. $p<0.05$; b: significantly different from group $3, p<0.05$.

Table 2. The results of histopathological score in all groups.

\begin{tabular}{ll}
\hline Groups & Histopathological score \\
\hline Group 1 (sham) $(n=6)$ & $0.12 \pm 0.35$ \\
\hline Group 2 (PH) $(n=8)$ & $1.37 \pm 0.74^{a}$ \\
\hline Group 3 (SLM+PH) $(n=8)$ & $0.37 \pm 0.51^{b . c}$ \\
\hline Group 4 (SLM+SDOA+PH) $(n=8)$ & $0.50 \pm 0.53^{b . c}$ \\
\hline Group 5 (SDOA+PH) $(n=8)$ & $0.75 \pm 0.70^{b}$
\end{tabular}

asignificant increase $(p<0.05)$,vs. sham group. 'bignificant decrease $(p<0.05)$, vs. $\mathrm{PH}$ group. 'Significant decrease $(\mathrm{p}<0.05)$, vs. $\mathrm{PH}+\mathrm{SDOA}$ group.

Table 3. Mean number of cells stained with PCNA in liver.

\begin{tabular}{|c|c|}
\hline Groups & The numbers of PCNA (+) cell \\
\hline Group 1 (sham) $(n=6)$ & $3.62 \pm 1.06$ \\
\hline Group $2(P H)(n=8)$ & $5.56 \pm 1.35^{a}$ \\
\hline Group $3(\mathrm{SLM}+\mathrm{PH})(\mathrm{n}=8)$ & $6.84 \pm 1.39^{\text {a.b. } c ~}$ \\
\hline Group $4(\mathrm{SLM}+\mathrm{SDOA}+\mathrm{PH})(\mathrm{n}=8)$ & $7.04 \pm 1.36^{\text {a.b. c }}$ \\
\hline Group $5(\mathrm{SDOA}+\mathrm{PH})(\mathrm{n}=8)$ & $6.11 \pm 1.23^{a . b}$ \\
\hline $\begin{array}{l}\text { asignificant increase }(p<0.05), \\
(p<0.05), v s . \mathrm{PH} \text { group. cSignificant }\end{array}$ & $\begin{array}{l}\text { vs. Sham group. bSignificant increase } \\
\text { increase }(p<0.05) \text {, vs. SDOA group }\end{array}$ \\
\hline
\end{tabular}

Table 4. The levels of liver tissue biochemical parameters were given with mean $\pm S D$.

\begin{tabular}{|c|c|c|c|c|c|}
\hline $\begin{array}{l}\text { Groups } \downarrow \\
\text { parameters } \rightarrow\end{array}$ & SOD & CAT & & MDA & GSH \\
\hline Group 1 (sham) $(n=6)$ & $2.38 \pm 0.18$ & $\begin{array}{l}304.83 \\
39.21\end{array}$ & \pm & $3951 \pm 8.26$ & $\begin{array}{l}45.58 \\
7.92\end{array}$ \\
\hline Group $2(\mathrm{PH})(\mathrm{n}=8)$ & $2.32 \pm 0.14$ & $\begin{array}{l}299.47 \\
23.60\end{array}$ & \pm & $\begin{array}{l}57.64 \\
7.41^{a}\end{array}$ & $\begin{array}{l}29.92 \\
2.72^{d}\end{array}$ \\
\hline
\end{tabular}

\begin{tabular}{|c|c|c|c|c|c|c|c|c|c|}
\hline $\begin{array}{l}\text { Group } \\
(n=8)\end{array}$ & 3 & $(\mathrm{SLM}+\mathrm{PH})$ & $2.29 \pm 0.06$ & $\begin{array}{l}290.97 \\
34.23\end{array}$ & \pm & $\begin{array}{l}45.79 \\
4.96^{\text {b.c }}\end{array}$ & \pm & $\begin{array}{l}33.01 \\
7.48^{\mathrm{e}}\end{array}$ & \pm \\
\hline $\begin{array}{l}\text { Group } \\
+\mathrm{PH})(\mathrm{n}\end{array}$ & $\begin{array}{c}4 \\
1=8)\end{array}$ & SLM+SDOA & $2.34 \pm 0.13$ & $\begin{array}{l}287.55 \\
18.45\end{array}$ & \pm & $\begin{array}{l}40.84 \\
5.15^{\text {b.c }}\end{array}$ & \pm & $\begin{array}{l}35.55 \\
3.11^{\mathrm{e}}\end{array}$ & \pm \\
\hline $\begin{array}{l}\text { Group } \\
(n=8)\end{array}$ & 5 & $(\mathrm{SDOA}+\mathrm{PH})$ & $2.54 \pm 0.22$ & $\begin{array}{l}295.66 \\
25.96\end{array}$ & \pm & $55.51 \pm 4$ & 34 & $\begin{array}{l}30.53 \\
4.70\end{array}$ & \pm \\
\hline
\end{tabular}

asignificant increase $(p<0.05)$, vs. sham, bSignificant decrease $(p<0.05), v s$. $P H$, cSignificant decrease $(p<0.05)$, vs. SDOA+PH, dSignificant decrease $(p<0.05)$, vs. sham, esignificant increase $(p<0.05)$, vs. PH

\section{Conclusion}

Our results showed the remarkable protective effects of silymarin rather than SDOA based on the histopathological and PCNA findings and liver tissue/serum biochemical parameters, but only SDOA consumption or SDOA+silymarin combination should not be overlooked. Therefore, before 7 and after $10 \mathrm{~d}$ of PH operations, silymarin application and SDOA consumption have more beneficial effects on the regenerative capacity of remnant liver. This situation may be probably due to their antioxidative and immunomodulatory properties. Therefore, alone SDOA consumption or silymarin combination may be an effective pharmacological strategy to improve liver dysfunction or enhance the regenerative capacity in the case of $\mathrm{PH}$.

\section{Acknowledgments}

This study was supported by the Scientific Research Fund of Inonu University (Project number: (2014/28). The authors would like to express profound thanks for the financial support to the Unit of Scientific Research Projects of Inonu University. Additionally, we would like to thank Associate Prof. Dr. Turan ARABACI, Inonu University Pharmacy Faculty and Department of Pharmaceutical Botany for the botanical supports he provided. 


\section{References}

1. Zabielski $\mathrm{P}$, Baranowski $\mathrm{M}$, Zendzian-Piotrowska $\mathrm{M}$. Partial hepatectomy activates production of the pro-mitotic intermediates of the sphingomyelin signal transduction pathway in the rat liver. Prostagland Lipid Med 2007; 83: 277-284.

2. Yao XM, Zhao J, Li Y, Li Y. Effects of bicyclol on liver regeneration after partial hepatectomy in rats. Dig Dis Sci 2009; 54: 774-781.

3. Kahlon TS, Smith GE. In vitro binding of bile acids by bananas, peaches, pineapple, grapes, pears, apricots and nectarines. Food Chem 2007; 101: 1046-1051.

4. Yilmaz I, Karaman A, Vardi N. Effects of organic apricot on liver regeneration after partial hepatectomy in rats. Transplantat Proc 2013; 45: 2455-2460.

5. Ruiz D, Egea J, Gil MI, Tomas-Barberan FA. Characterization and quantitation of phenolic compounds in new apricot (Prunus armeniaca L.) varieties. J Agric Food Chem 2005; 53: 9544-9552.

6. Vardi N, Parlakpinar H, Ozturk F. Potent protective effect of apricot and $\beta$-carotene on methotrexate-induced intestinal oxidative damage in rats. Food Chem Toxicol 2008; 46: 3015-3022.

7. Yang CC, Fang JY, Hong TL. Potential antioxidant properties and hepatoprotective effects of an aqueous extract formula derived from three Chinese medicinal herbs against CCl4-induced liver injury in rats. Int Immunopharmacol 2013; 15: 106-113.

8. Bishayee A, Politis T, Darvesh AS. Resveratrol in the chemoprevention and treatment of hepatocellular carcinoma. Cancer Treat Rev 2010; 36: 43-53.

9. El-Adawi H, El-Azhary D, Abd El-Wahab A. Protective effect of milk thistle and grape seed extracts on fumonisin B1 induced hepato- and nephro-toxicity in rats. J Med Plant Res 2011; 5: 6316-6327.

10. Pilat L, Mihali C, Herman H. Pharmacology of Silybum marianum and its active constituents. therapeutic activitypart 1. J Med Aradean 2011; 14: 25-33.

11. Sidhu MC, Saini P. Silybum marianum: a plant of high medicinal importance-a review. W J P R 2012; 1: 72-86.

12. Kadereit JW, Jeffrey C. Flowering plants. eudicots: asterales. The Families and Genera of Vascular Plants 2007; 132.

13. Ozturk M, Akdogan M, Keskin I. Effect of Silybum marianum on acute hepatic damage caused by carbon tetrachloride in rats. Biomed Res 2012; 23: 268-274.

14. Ding T, Tian S, Zhang Z, Gu D, Chen Y, Shi Y, Sun Z. Determination of active component in silymarin by RP-LC and LC/MS. J Pharm Biomed Anal 2001; 26: 155-161.

15. Suchy P, Strakova E, Kummer V. Hepatoprotective effects of milk thistle (Silybum marianum) seed cakes during the chicken broiler fattening. Acta Vet Brun 2008; 77: 31-38.

16. Wu JW, Tsai TH. Effect of silibinin on the pharmacokinetics of pyrazinamide and pyrazinoic acid in rats. Drug Metab Dispos 2007; 35: 1603-1610.
17. Higgins GM, Anderson AR. Experimental pathology of the liver. Restoration of the liver of the white rat following partial surgical removal. Arc Pathol 1931; 12: 186-202.

18. Bradford MM. A rapid and sensitive method for the quantitation of microgram quantities of protein utilizing the principle of protein-dye binding. Anal Biochem 1976; 72: 248-254.

19. Buege JA, Aust SD. Microsomal lipid peroxidation. Methods Enzymol 1978; 52: 302-310.

20. Akerboom TP, Sies. Assay of glutathione, glutathione disulfideand glutathione mixed disulfides in biological samples. Met Enzymol 1981; 77: 373-383.

21. McCord JM, Fridovich I. Superoxide dismutase. An enzymic function for erythrocuprein (hemocuprein). J Biol Chem 1969; 244: 6049-6055.

22. Luck H. Methods of enzymatic analysis. Verlag Chemie Academic Press New York USA 1963; 885-888.

23. Chen IS, Chen YC, Chou CH. Hepatoprotection of silymarin against thioacetamide-induced chronic liver fibrosis. J Sci Food Agric 2012; 92: 1441-1447.

24. Horvath ME, Gonzalez-Cabello R, Blazovics A. Effect of silibinin and vitamin $\mathrm{E}$ on restoration of cellular immune response after partial hepatectomy. J Ethnopharmacol 2001; 77: 227-232.

25. Raskovic A, Stilinovic N, Kolarovic J. The protective effects of silymarin against doxorubicin-induced cardiotoxicity and hepatotoxicity in rats. Molecules 2011; 16: 8601-8613.

26. Megahed HA, Zahran HG, Arbid MS. Comparative study on the protective effect of Biphenyl Dimethyl Dicarboxylate (DDB) and Silymarin in hepatitis induced by carbon tetrachloride (CCl4) in rats. N Y Sci J 2010; 3: 1-11.

27. Yilmaz I, Temel I, Gürsoy S, Dogan Z. The effects of apricot on serum proteins and liver enzymes in rats. J Food Nutrit Res 2013; 52: 101-106.

28. Parlakpinar H, Olmez E, Acet A. Beneficial effects of apricot-feeding on myocardial ischemia reperfusion injury in rats. Food and Chem Toxicol 2009; 47: 802-808.

29. Yilmaz I, Cetin A, Bilgic Y. Hepatoprotective effects of apricot against acetaminophen-induced acute hepatotoxicity in rats. AJPS 2015; 3: 44-48.

30. Tsujii H, Okamoto Y, Kikuchi E, Matsumoto M, Nakano H. Prostaglandin E2 and rat liver regeneration. Gastroenterology 1993; 105: 495-499.

31. Wang HH, Lautt WW. Evidence of nitric oxide, a flow dependent factor, being a trigger of liver regeneration in rats. Can J Physiol Pharmacol 1998; 76: 1072-1079.

32. Trejo-Solis C, Chagoya de Sanchez V, Aranda-Fraustro A. Inhibitory effect of vitamin $\mathrm{E}$ administration on the progression of liver regeneration induced by partial hepatectomy in rats. Lab Inves 2003; 83: 1669-1679.

33. Uyanoglu M, Canbek M, Aral E, Baser KHC. Effects of carvacrol upon the liver of rats undergoing partial hepatectomy. Phytomed 2008; 15: 226-229.

34. Togo S, Chen H, Takahashi T, Kubota T, Matsuo K, Morioka D, Watanabe K, Yamamoto H, Nagashima Y, 
Shimada H. Prostaglandin E1 improves survival rate after 95\% hepatectomy in rats. J Surg Res 2008; 146: 66-72.

35. Kirimlioglu H, Ecevit A, Yilmaz S. Effect of resveratrol and melatonin on oxidative stress enzymes, regeneration, and hepatocyte ultrastructure in rats subjected to $70 \%$ partial hepatectomy. Transplant Proc 2008; 40: 285-289.

36. Malik R, Mellor N, Selden C, Hodgson H. Triiodothyronine enhances the regenerative capacity of the liver following partial hepatectomy. Hepatology 2003; 37: 79-86.

37. Saribeyoglu K, Aytac E, Pekmezci S. Effects of clinoptilolite treatment on oxidative stress after partial hepatectomy in rats. Asian J Surg 2011; 34: 153-157.

38. El-Sayed NS, Rizk SM. The protective effect of quercetin, green tea or malt extracts against experimentally-induced lung fibrosis in rats. Afric J Pharm Pharmacol 2009; 3: 191-201.

39. Osadebe PO, Okoye FBC, Uzor PF. Phytochemical analysis, hepatoprotective and antioxidant activity of Alchornea cordifolia methanol leaf extract on carbon tetrachloride-induced hepatic damage in rats. Asian Pacific J Tropic Med 2012; 5: 289-293.

40. Seehofer D, Schirmeier A, Bengmark S. Inhibitory effect of curcumin on early liver regeneration following partial hepatectomy in rats. J Surg Res 2009; 155: 195-200.

41. Akcan A, Kucuk C, Ok E. The effect of amrinone on liver regeneration in experimental hepatic resection model. $\mathrm{J}$ Surg Res 2006; 130: 66-72.

42. Yilmaz I, Dogan Z, Soysal H. The effects of dried apricot supplementation on daily food intake in rats. Turk J Pharma Sci 2013; 10: 137-144.

\section{*Correspondence to}

İsmet Yilmaz

Department of Pharmacology

Inonu University

Turkey 